\title{
Botox: The Deadly Beauty
}

\author{
Nang Khin Mya ${ }^{1 *}$, Yeap Boon Tat', Boon Seng Yeoh², Win Tin'1, Tun Aung1, Firdaus Hayati ${ }^{1}$ \\ ${ }^{1}$ Faculty of Medicine \& Health Sciences, Universiti Malaysia Sabah, Kota Kinabalu, Malaysia \\ ${ }^{2}$ Department of Physiology, School of Medical Sciences, Health Campus, Universiti Sains Malaysia, \\ Kubang Kerian, Malaysia \\ Email: *nkhinmya@gmail.com
}

How to cite this paper: Mya, N.K., Tat, Y.B., Yeoh, B.S., Tin, W., Aung, T. and Hayati, F. (2019) Botox: The Deadly Beauty. Forensic Medicine and Anatomy Research, 7, 13-17.

https://doi.org/10.4236/fmar.2019.71003

Received: October 3, 2018

Accepted: December 5, 2018

Published: January 2, 2019

Copyright $\odot 2019$ by authors and Scientific Research Publishing Inc. This work is licensed under the Creative Commons Attribution International License (CC BY 4.0). http://creativecommons.org/licenses/by/4.0/

\begin{abstract}
Botox injection is the best known as a group of medication that uses various forms of Botulinum toxin A to temporarily paralyze muscle. It primarily reduces the appearance of some facial wrinkles and it is known as Botox Cosmetic. It is a popular treatment among people who want to achieve younger look. A 34-year-old female collapsed at beauty salon soon after receiving Botox injection. Although resuscitation was done in the emergency unit, hospital, she could not be revived and succumbed to death. This case report highlights the rare case of sudden death after Botox injection. We would like people to raise the awareness of unexpected occurrence after Botox injection while they make themselves beautify.
\end{abstract}

\section{Keywords}

Botulinum Toxin, Sudden Death, Botox Injection

\section{Introduction}

Botulinum neurotoxins (BoNTs) are the most potent natural toxins that are produced by various toxigenic strains of spore-forming anaerobic Clostridium Botulinum. They act as metalloproteinases that enter peripheral cholinergic nerve terminals and cleave proteins that are crucial components of the neuroexocytosis apparatus, causing a persistent but reversible inhibition of neurotransmitter release resulting in flaccid muscle paralysis. It is the most commonly injected substance that reduces the appearance of some facial wrinkles, thus people choose to achieve younger look [1].

In September 2005, the FDA said that use of Botox has resulted in 28 deaths between 1989 and 2003, though none were attributed to cosmetic use [2]. The most common local side effect is swelling or bruising at the injection site. Se- 
rious local reactions have been reported that includes blurred vision, swelling, itchiness and dry mouth. As a systematic reaction, it causes headache or flu-like symptoms. Moreover, it can cause urinary retention, breathing difficulty, dysphagia, dysphonia and/or dyspnea after Botox injection [3].

\section{Case Report}

A healthy 34-year-old lady was collapsed at the beauty salon shortly after giving Botox injection. According to her past history, she received Botox intramuscular injection 5 times previously and didn't experience any allergic reaction. She was sent to the emergency unit in a nearby hospital where resuscitation was done, but she could not be revived and expired. Autopsy was done to find out the cause of death. The resuscitation procedures as she was given were intravenous injection of hydrocortisone $200 \mathrm{mg}$, intramuscular injection of adrenaline 500 micrograms $(0.5 \mathrm{ml}$ of adrenaline $1 / 1000)$.

These are procedures of resuscitation but this lady was not given because she expired suddenly. The dose may be repeated several times at 5-minute interval according to blood pressure, pulse rate and respiratory condition. Intravenous injection of anti botulinum serum (one dose of commercial serum, consisting of $750 \mathrm{IU}$ of antitoxin A, $500 \mathrm{IU}$ antitoxin B and $50 \mathrm{IU}$ antitoxin E.) and intramuscular injection of neostigmine $0.5 \mathrm{mg}$ can be given as well.

At autopsy, the length of the body was $155 \mathrm{~cm}$. The face was congested, cyanosed and nail beds were cyanosed too. There was a group of small hemorrhagic spots at the injection site, right temporal area. There were bruises \& swelling measured $4.5 \times 5 \mathrm{~cm}$ over left temporal area with hemorrhagic injection marks. Bruise measured $6.5 \times 5 \mathrm{~cm}$ over right side of the neck, multiple tiny hemorrhagic spots around the mouth \& nose were noted.There was no external injury apart from them.

Internally, there was anextra cranial hematoma $8 \times 6 \mathrm{~cm}$ over the left temporal area. There was a large hematoma over the right sternomastoid muscle as a result of resuscitation. The right lung weighed $360 \mathrm{gm}$, left lung was $430 \mathrm{gm}$ and histological features revealed marked congestion of alveolar capillaries with focal intra alveolar hemorrhages and edema. Liver weighed 1600 gm, marked congestion of central veins and sinusoids with central hemorrhagic necrosis and degeneration parenchymal cells were noted. Changes of other organs were unremarkable.

Blood and urine for toxicological examination expressed that the Botulinum toxin was not identified. Based on external findings, gross and microscopic features of the internal organs, the cause of death was opined as hypersensitivity due to Botox injection.

In this case, although laboratory detection of botulinum toxin was not recorded, past and current history of patient, clinical findings (as described above), gross and microscopic findings of internal organs favour the condition of hypersensitivity. According to the theory, hypersensitivity is usually documented 
by a positive skin test, which can be treated by the administration of antihistamines and systemic corticosteroids.

\section{Discussion}

Botulinum toxin is an injectable neurotoxin used for the treatment of migraines, strabismus, limb spasticity. Botulinum toxin A is preferred for its long duration of action and easy production [2]. It is marketed under the brand names Botox and Xeomin. By its cholinergic action, it causes the relaxation of muscles surrounding the injection site [4]. The Botulinum toxin A, marketed as BOTOX, was recently approved by the Food and Drug Administration for cervical dystonia and glabella wrinkles. It has been well received due to its efficacy in improving facial lines [5] [6].

One literature expressed a serious systemic reaction of a Box-lidocaine combination resulting in death. In that case, the patient had been treated with a therapeutic dose of Botox mixed with lidocaine, therefore Botox could not be proven as the cause of death [5]. Although the anaphylaxis cannot be definitively proven to be due to Botox alone, the case warns of an adverse reaction related to Botox, a drug that is rapidly expanding in range of use as well as increased usage [5] [6] [7].

One experimental study showed the pharmacologically-defined Standard Unit of Botox which is based on the lethal dose (LD 50) of Botulinum type A toxin [1] [7]. Clinically, the Standard Unit serves as an important unit of measurement and reference. A typical clinical application varies from 4 to 20 units for cosmetic purposes to up to 300 units for therapeutic purposes [2].

Usually, the treatment process regarding cosmetic Botox is safe and simple. The treatment procedure of Botox is very quick and in most of the cases, it takes less than 20 minutes. One of the major advantages of Botox is a little or no recovery time, and most people feel fine and can return to their normal life immediately after treatment [8]. The side effects of Botox were mentions earlier. If the injections aren't placed correctly, the medication may spread into adjacent tissues and cause problems such as; Eyelid droop, cockeyed eyebrows, crooked smile, dry eye or excessive tearing. Although it is very unlikely, there is a possibility that the effect of botulinum toxin may spread to other parts of the body and cause botulism-like signs and symptoms [8].

A case series of 4 patients with symptoms consistent with naturally occurring botulism was published in 2006 Nov. by Chertow et al. On November 27, 2004, 4 suspected botulism case-patients with a link to cosmetic botulinum toxin injections were reported. In all cases patients had been injected with a highly concentrated, unlicensed preparation of Botulinum toxin $\mathrm{A}$ and may have received doses 2857 times the estimated human lethal dose by injection [9].

In our case, deceased had received Botox injection five times but no such reaction occurred before. She received the injection at beauty salon, thus we were not sure the procedure, brand used and sterilization. Moreover, we were 
not able to prove the correct dosage \& manufacture and preparation.

\section{Conclusion}

Forensic pathologist needs to exclude or confirm other non-toxic factors to give opinion as the Cause of Death. Collection of suitable samples, analysis \& interpretation of the lab results in the light of knowledge with case history, clinical features and autopsy findings will help to provide the final opinion. We present the case to give message that "Death may occur in so-called generally considered to be a very safe procedure". Physicians and patients should be aware of the hazards associated with illegitimate use of unlicensed Botulinum toxin products. Only licensed products should be used clinically. Entities inappropriately marketing, selling, or using unlicensed Botulinum toxin products should be sought and subjected to full criminal and civil penalties. This case report highlights the rare case of sudden death after Botox injection. We would like people to raise the awareness of unexpected occurrence after Botox injection although people make themselves beautify.

\section{Conflicts of Interest}

The authors declare no conflicts of interest regarding the publication of this paper.

\section{References}

[1] Kukreja, R. and Singh, B.R. (2009) Botulinum Neurotoxins: Structure and Mechanism of Action. Microbial Toxins: Current Research and Future Trends. Caister Academic Press.

[2] Montecucco, C. and Molgó, J. (2005) Botulinal Neurotoxins: Revival of an Old Killer. Current Opinion in Pharmacology, 5, 274-279. https://doi.org/10.1016/j.coph.2004.12.006

[3] Irvine, CA. (2012) BOTOX Cosmetic Product Information: BOTOX Cosmetic (onabotulinumtoxinA). http://www.allergan.com/products/medical_aesthetics/botox_cosmetic.htm

[4] Lorne, K.R., Kristen, A.T. and Grace, S. (2014) The First Case Report of a Systemic Allergy to OnabotulinumtoxinA (Botox) in a Healthy Patient. Aesthetic Surgery Journal, 34, 766-768.

[5] Li, M., Goldberger, B.A. and Hopkins, C. (2005) Fatal Case of BOTOX-Related Anaphylaxis? Journal of Forensic Sciences, 50, 169-172. https://doi.org/10.1520/JFS2004196

[6] Robert, A.H. (2017) FDA Approves Botox to Treat Chronic Migraines: BOTOX (R) Injections in Plastic Surgery WebMD.

[7] Khoklov, V.D., Krut, M.I. and Shashko, S. (2012) Anaphylactic Shock Following Administration of Lidocaine after Negative Skin Test. Klin Med (Mosk), 90, 62-64. (In Russian)

[8] Coté, T.R., Mohan, A.K., Polder, J.A., Walton, M.K. and Braun, M.M. (2005) Botulinum Toxin Type A Injections: Adverse Events Reported to the US Food and Drug Administration in Therapeutic and Cosmetic Cases. Journal of the American Academy of Dermatology, 53, 407-415. https://doi.org/10.1016/j.jaad.2005.06.011 
[9] Daniel, S.C., Esther, T.T. and Susan, E. (2006) Botulism in 4 Adults Following Cosmetic Injections with an Unlicensed, Highly Concentrated Botulinum Preparation. JAMA, 296, 2476-2479. https://doi.org/10.1001/jama.296.20.2476 